\title{
Gamification of the work floor: A literature review of gamifying production and logistics operations
}

\author{
Harald Warmelink \\ NHTV Breda University of \\ Applied Sciences \\ warmelink.h@nhtv.nl
}

\author{
Jonna Koivisto \\ Tampere University of \\ Technology \\ jonna.koivisto@tut.fi
}

\author{
Igor Mayer \\ NHTV Breda University of \\ Applied Sciences \\ mayer.i@nhtv.nl
}

\author{
Mikko Vesa \\ Hanken School of Economics \\ mikko.vesa@hanken.fi
}

\author{
Juho Hamari \\ Tampere University of Technology \\ juho.hamari@tut.fi
}

\begin{abstract}
We review the current body of academic literature concerning gamification of production and logistics. The findings indicate that production execution and control has been addressed most often in the current body of literature, which consists mostly of design research. Objectives and goals, points, achievements, multimedial feedback, metaphorical/fictional representations, and levels and progress are currently most often employed gamification affordances on this field. The research has focused on examining or considering motivation, enjoyment and flow as the main psychological outcomes of gamification in the given context, while individual performance and efficiency are the most commonly examined or suggested behavioral/organizational impacts. Future studies should employ more rigorous study designs and firmly ground the discussions in organization theory.
\end{abstract}

\section{Introduction}

Recently, the design approach of gamification [10][13][14][34] has started to gather the attention of academics and practitioners as a way to increase performance of production and logistic operations in real-life organizational contexts [34]. Constituting a part of a larger cultural and societal development of games and gameful interaction permeating aspects of everyday life and work, the concept of gamification is often used to refer to the design approach of implementing elements (affordances, mechanics, technologies) familiar from games to contexts where they are not commonly encountered [10][13][14]. The goal of gamification is typically to induce experiences common to gaming, and to create and increase motivation or engagement via these experiences. At the core of gamification applications is not only the entertainment or enjoyment of the system use itself, but the external consequences that the system motivates the user towards [13][14], e.g. individual behavior and activities or organizational performance. In an organizational context, gamification does not take employees out of their actual work environment into an educational or training situation, unlike simulation and serious games. Instead, gamification intervenes directly in daily operations through game mechanics, with or without the aid of some game technology. An essential aspect of gamification implementations is indeed their nature as seeking to enhance the core activity with the gameful experiences without interfering with or impeding the main activities [20][13][14].

The general understanding of gamification, whether the intended results can be achieved with it, and how these results can be reached, is still evidently in development. More research is required for developing a solid theoretical as well as methodological base on which research knowledge can accumulate (see e.g. [12][32]). Furthermore, as the outcomes of gamification are highly dependent on contextual factors, research in specific domains and areas is required. Thus far, the literature on gamification has been mostly focused on the domains of education, crowdsourcing and health [12][23], with most other domains gaining only limited attention. However, as the general body of literature on gamification keeps growing, more varied domains and perspectives are being investigated.

Thus far, organizational contexts, ranging from management to various forms of services and industrial processes, have been among the less studied domains for gamification. However, as the potential of gamification is being increasingly discussed in various organizational contexts (e.g. [34]; see also 
'gamification of work' in [4][7]), more research on the topic can be expected to be published in coming years. As we demonstrate in this paper, the interest in gamification of the production and logistics work floor has increased over the past five years. We consider this to be the case, for example, for the following reasons. Firstly, production and logistics work is often mundane given its highly structured, standardized and repetitive nature. If gamification delivers its promise, it could improve workers' enjoyment and work satisfaction, and consequently, organizational performance. Secondly, over the past decade, sensor technologies have heavily permeated the production and logistics work floor [37] rendering it easier to connect gathered work data to common gamification technologies and principles, such as scoring systems and leaderboards. Thirdly, the cost-efficiency of automating very complex work in this domain is often still too low [17]. Investing in the workers, the work processes and conditions is still often seen as more attractive, and thus gamification can provide an interesting possibility. With the increase of interest in gamification, there is a need to start developing a body of knowledge on gamification design and impact for this rather particular domain of work.

To contribute to this developing field and to promote future research on gamification in organizational contexts, we review the research literature on gamification on the production and logistics work floor with the goals of understanding the status quo and providing suggestions for future research. More specifically this study reviews which aspect(s) of production or logistics operations have been addressed in the body of literature, what research methodologies have been employed, what motivational affordances have been applied or considered, and what have been the expected and/or measured psychological, behavioral or organizational outcomes and impacts, desired or undesired.

\section{Background}

\subsection{Production and logistics}

Evidently, production and logistics together comprise a large field and pertain to a wide variety of processes (see e.g. [6][5][3]), all of which could be individually considered from the perspective of gamification. In this study, we focus on the primary process of production and logistics, i.e., the operational core's work that often takes place on or in a factory floor, warehouse, truck, train, ship or airplane. We further demarcate our review by working from the assumption that the primary process of production and logistics consists of designers, engineers, managers and laborers involved in the mass scale production of products and services that, in the end, are delivered to their place of consumption.

In order to categorize the various aspects and processes in the primary processes of production and logistics, we divide them in the following manner: 1) product and process engineering, 2) production planning, 3) production execution and control, 4) supply chain design and planning, and 5) transportation planning and execution. With product and process engineering we refer to the development and/or implementation of interconnected technologies, machines or processes for efficient mass production of a deliverable product or service at one or more locations. Production planning refers to the efficient organization of the entire production process, from e.g. the timely delivery of necessary technologies and materials from the supply chain to the arrangement of the required personnel. Production execution and control refers to completing tasks in the actual production process. This includes ensuring that the entire production process is continued from start to finish and an intended quality level of the work is reached. Rectifying faults and managing unforeseen events or outcomes is also a part of production control. With supply chain design and planning we refer to the design and efficient organization of the delivery of technologies, materials, products and services required for production processes to their appropriate locations. Finally, transportation planning and execution refers to moving and temporarily storing technologies, materials and products, often via intermediary steps or hubs, to their point of use/consumption.

\subsection{Gamification}

Gamification broadly refers to design that attempt to transform e.g. various systems, services, activities and organizations into more game-like [14][34]. Gamification, therefore, commonly involves the use of game design as means to invoke similar experiences as games do and further affect people's behavior (in contexts not traditionally perceived as games or gameful) [14][34]. Therefore, gamification can further be broken down to three primary elements of interest [13][14]: the gamification design, psychological mediators/outcomes and behavioral outcomes (see Figure 1).

The gamification design commonly consists of affordances that build on game design and interactions that are common in games. With affordances we refer to designed properties of a system, either perceived or actual, that determine how a person may use the given system [24]. A user of a system is not compelled to act 
upon these properties; instead, they rather "enable" actions, in case the user perceives them and chooses to act upon them. In the context of gamification, the affordances most often refer to various design elements common to games.

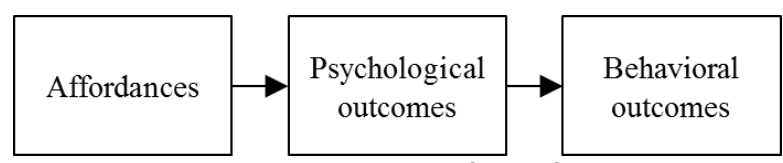

Figure 1. The conceptualization of gamification based on [13] and [14]

The psychological outcomes refer to any psychological effects and experiences that the gamification implementation is seeking to support the user towards. These are experiences and effects that are commonly thought to be induced by games, for example, senses of mastery and competence, relatedness and sense of community, creativity and playfulness, enjoyment and flow (see e.g. [30]). All of these aspects are commonly connected to intrinsic motivations and to the "gameful" experiences in the gamification literature (see e.g. [10][22][13][14][29]). Finally, the behavioral outcomes refer to any activities or behaviors that the gamification seeks to support.

Gamification is usually situated in a certain context and attempts to elicit some behavior related to that context (see e.g. [12][14][9]). Therefore, the domain where gamification is situated, the social and cultural context where the activity takes place, and the demographic and individual characteristics of the users are important aspects to consider in the gamification design and research. Prior research on gamification has indicated that e.g. demographic factors influence how the gamification is perceived [16]. Furthermore, the domain of the activity and how it is perceived may affect the users' willingness to engage with the gameful features [11]. Consequently, results regarding the effectiveness of a gamification system from one domain do not necessarily translate easily to other domains. Therefore, research on gamification in the various contexts where it is being employed is direly needed.

This study, in particular, attempts to bring clarity related to gamification in the context of production and logistics through investigation of the affordances, psychological outcomes and behavioral outcomes in the related literature. Moreover, we extend our review to include organizational impacts (e.g. increases in turnover or profit). We expected that this was often actually targeted or at least connected to the behavioral impacts by the involved organizations.

\section{Review procedure}

The literature search was conducted in the Scopus database in 5/2017. The Scopus indexes contents of all other databases with potentially relevant content, e.g. ACM, IEEE, Springer, and the DBLP Computer Science Bibliography. Using only one database instead of several was considered a preferable method in order to increase the rigor, clarity and replicability of the literature search process [25].

The following search string was used for the Scopus search: (TITLE-ABS-KEY(gamif*) AND TITLE-ABS-KEY(logistic*) OR TITLE-ABS$\mathrm{KEY}$ (production)). Thus the search returned entries with a mention of gamification or some form of the commonly used root verb 'gamify' and either the term 'logistic' or 'production'. The search string was limited to return only such hits where these terms existed in the metadata, that is, in the title, abstract or keywords. No other limitations in terms of e.g. publication type (a journal article, a short/full conference paper, a workshop paper) or type of paper (theoretical/empirical study) were employed.

The literature search resulted in 103 hits, which were further inspected for inclusion or exclusion with the following criteria: 1) the entry was a research paper, and not e.g. a proceeding summary or a conference review, an editorial, or a book introduction, 2) the research paper was written in English, 3) the paper was related to logistics or production as defined in the introduction of this paper, and 4) the paper was not focused on the use of games in or the gamification of formal education (i.e., at educational institutes) concerning production and logistics or the paper was not discussing actual gamification on the primary process level in production and logistics. This means that we omitted common supportive and foundational aspects of production and logistics business, such as corporate strategy, finances, human resource management, marketing, sales or ICT support. Furthermore, one duplicate study was identified. Of the duplicates, the paper published later was included in the review.

After inspecting the search hits following the described criteria, 18 papers were initially identified as the body of literature to be reviewed. We then conducted a backward-forward search on the references of and citations to these 18 papers. This procedure did not reveal any new papers that would have fit to the above-described criteria for inclusion. Therefore, the final body of literature consists of the 18 studies. The literature search procedure is reported in Figure 2. A full list of the 18 studies is provided in the Appendix A. In the text, the reviewed studies are referred to with the appendix IDs: A1, A2, etc. 

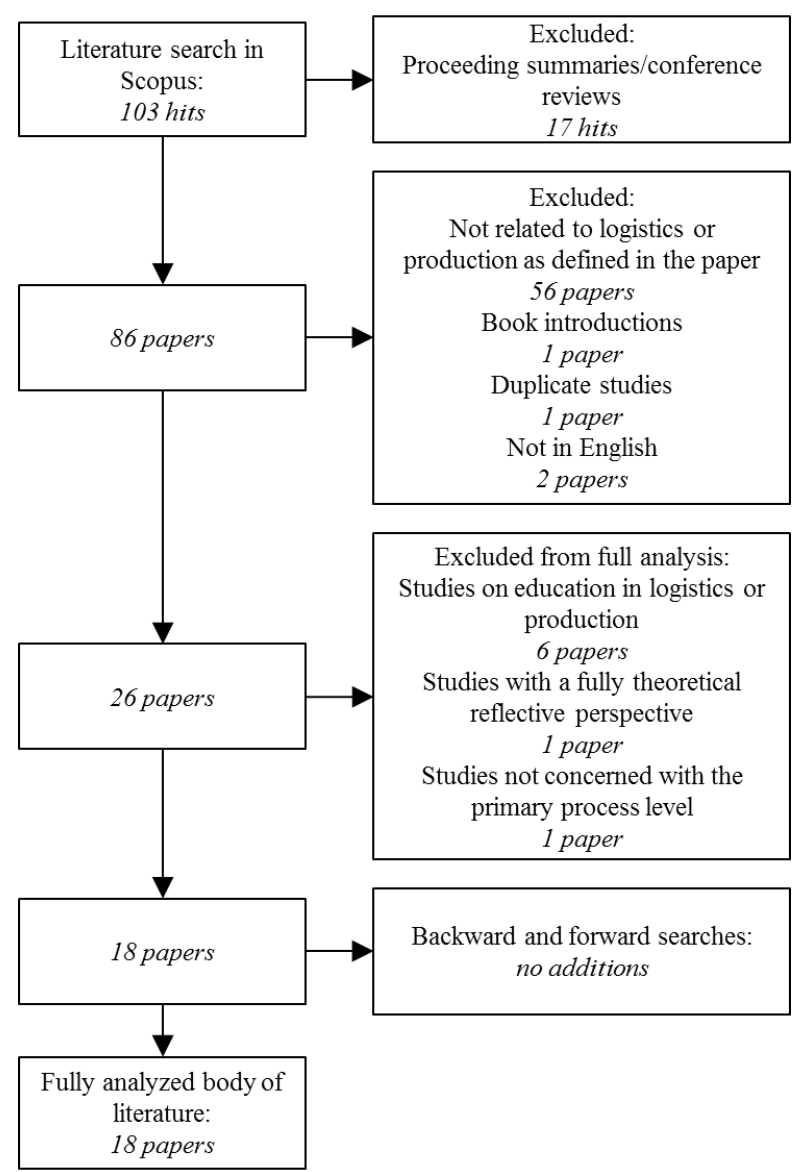

Figure 2. A flowchart describing the literature search procedure.

After the identification of the relevant body of literature, the papers were analyzed, firstly, authorcentrically, and secondly, concept-centrically, following the guidelines of Webster and Watson [35]. In the author-centric coding phase the pre-defined units of analysis were examined and coded for each paper as it was read. This procedure lead to a matrix of coded literature. In the concept-centric phase the coded literature was then organized based on the units of analysis. During this step of the process, the coded concepts were comprised into frequency tables (see [35]), which form the core of this review. Thus, the frequency tables present the units of analysis as well as the coding used in the analysis process.

\section{Review}

Regarding the subdomains of production and logistics work outlined above, the gamification studies were mostly concerned with the production execution and control (15 out of 18 studies) (see Table 1). Furthermore, most of the studies examined gamification of these aspects in private or semi-public (sheltered work) organizations. For example, several publications offered results of different design iterations involving basic product assembly work in sheltered work organizations, applying motion recognition technology to automatically ascertain which step in the assembly process was being done, and using a projector to project visual feedback on the work table (A11-A13). The most common areas of industry in the reviewed literature were the automotive and construction industry. In the automotive industry, the tasks targeted by gamification were mainly different assembly tasks. In the construction area, the gamification targeted mainly planning of the work.

Table 1. Sub-branches of production and logistics connected to applied research methodologies in the reviewed studies. The numbers refer to Appendix IDs.

\begin{tabular}{|l|c|c|c|}
\hline & $\begin{array}{l}\text { Design- } \\
\text { conceptual/ } \\
\text { theoretical } \\
\text { studies }\end{array}$ & $\begin{array}{l}\text { Empirical, design research } \\
\text { studies }\end{array}$ \\
\hline & & $\begin{array}{l}\text { Evaluation } \\
\text { study }\end{array}$ & $\begin{array}{l}\text { (Quasi-) } \\
\text { Experiment }\end{array}$ \\
\hline $\begin{array}{l}\text { Product and } \\
\text { process } \\
\text { engineering }\end{array}$ & A17 & A1 & \\
\hline $\begin{array}{l}\text { Production } \\
\text { planning }\end{array}$ & A6, A7, A9, & A1, A11 & $\begin{array}{c}\text { A10, A12, } \\
\text { A13, A16, } \\
\text { A18 }\end{array}$ \\
\hline $\begin{array}{l}\text { Production } \\
\text { execution and } \\
\text { control }\end{array}$ & A14, A15, & A5 & \\
\hline $\begin{array}{l}\text { Trans- } \\
\text { portation } \\
\text { planning and } \\
\text { execution }\end{array}$ & A2 & & \\
\hline
\end{tabular}

Beyond the studies concentrating on the production execution and control, the other studies were either more generally oriented on (a sub-branch of) production and logistics, focused on an aspect of transportation planning and execution (e.g. improving truck driving efficiency by integrating different sensors in a single smartphone app offering achievements and other feedback), or focused on product and process engineering (complex event processing in any applicable production process). Supply chain design and planning was not considered on the actual primary process level. However, one management-level study examining gamification of global production chains was identified in the review process [26]. In this paper the problematics regarding the upper managements' IT solutions in handling global production were discussed and a gamified solution was suggested. 
Moreover, from a methodological perspective, most of the reviewed papers (11 out of 18 studies) were empirical, design research-based studies. In other words, in these studies, one or more prototypes or solutions had been designed or developed and then tested in an evaluation study or a (quasi-)experiment (see Table 1). While empirical research has thus been conducted, these studies, however, involved mostly handfuls of participants. Of the 11 empirical studies, those that reported a sample size had a minimum of 5 and maximum of 60 study participants. The average sample size was 26.6 and the median sample size 22 . What is noteworthy is that most of the evaluation and experimental work has been conducted in the actual work environments. Only a few studies were conducted in a laboratory setting, involving e.g. Lego bricks to simulate the participants' work.

The remaining seven publications were also designoriented in nature, but with a conceptual or theoretical orientation. These studies did not specifically report a test or an evaluation of a gamified solution. Some of these publications still involved some empirical data gathered through interviews with e.g. stakeholders. These studies have, however, not been categorized as empirical in this review. The conceptual/theoretical papers most often presented a design concept or prototype and discussed it in terms of, for example, psychological theories on motivation and flow, applicable (game-)technological advancements such as motion and emotional recognition or context-aware hard- and software, and the state-of-the-art knowledge in the given branch or aspect of production and logistics.

Concerning the research methods, the papers reporting an empirical study were mostly conducted using quantitative methods (7 out of 11 studies). Furthermore, 2 studies were conducted with mixed methods, one with only qualitative methods, and one study reported a simulation.

\subsection{Applied or considered motivational affordances}

In much of the gamification research and applications, the 'points, badges and leaderboards' triad has been a common way of implementing gamification despite the calls from scholars to widen the perspective and to consider the actual motivational aspects of what is being supported with the gamification [12][23][32][9]. Within the literature on gamification of production and logistics, the described triad exists among the applied affordances, but the elements are not the most commonly implemented ones (see Table 2).
Notably, the most commonly applied affordances in the body of literature were 'goals and objectives', followed by 'multimedial feedback', and 'metaphorical/fictional representations'. With the goals and objectives we refer to any clear, consecutive goals or objectives that players feel capable of understanding and pursuing immediately. With the multimedial feedback we refer to providing quick/immediate and very brief normative feedback on players' behavior, including any form of visual, audio or textual feedback. The metaphorical/fictional representations refer to audiovisual representations of the work and/or work environment involved, e.g., representing assembly work through Tetris (see e.g. studies A12 and A15).

Only after these elements, as the fourth, fifth and sixth most common categories, come the points, badges and leaderboards -related affordances. This is an interesting finding with regards to gamification literature in general (cf. [12][32]).

Table 2. The motivational affordances applied or considered.

\begin{tabular}{|c|c|}
\hline $\begin{array}{l}\text { Motivational } \\
\text { affordance category }\end{array}$ & $\begin{array}{l}\text { Number of publications } \\
\text { (Paper IDs from Appendix A) }\end{array}$ \\
\hline Goals and objectives & $\begin{array}{l}\mathbf{1 3}(\mathrm{A} 1, \mathrm{~A} 3, \mathrm{~A} 4, \mathrm{~A} 6, \mathrm{~A} 7, \mathrm{~A} 10, \\
\mathrm{A} 11, \mathrm{~A} 13, \mathrm{~A} 14, \mathrm{~A} 15, \mathrm{~A} 16, \mathrm{~A} 17, \\
\mathrm{~A} 18)\end{array}$ \\
\hline Multimedial feedback & $\begin{array}{l}\mathbf{1 2}(\mathrm{A} 1, \mathrm{~A} 6, \mathrm{~A} 7, \mathrm{~A} 8, \mathrm{~A} 9, \mathrm{~A} 10, \\
\mathrm{A} 11, \mathrm{~A} 12, \mathrm{~A} 13, \mathrm{~A} 14, \mathrm{~A} 15, \mathrm{~A} 17)\end{array}$ \\
\hline $\begin{array}{l}\text { Metaphorical/fictional } \\
\text { representation }\end{array}$ & $\begin{array}{l}11 \text { (A6, A7, A9, A10, A11, A12, } \\
\text { A13, A14, A15, A16, A18) }\end{array}$ \\
\hline Levels, progress & $\begin{array}{l}9(\mathrm{~A} 1, \mathrm{~A} 5, \mathrm{~A} 7, \mathrm{~A} 9, \mathrm{~A} 10, \mathrm{~A} 11, \\
\mathrm{A} 13, \mathrm{~A} 14, \mathrm{~A} 17)\end{array}$ \\
\hline $\begin{array}{l}\text { Points, credits, } \\
\text { achievements, rewards }\end{array}$ & $\begin{array}{l}9(\mathrm{~A} 1, \mathrm{~A} 3, \mathrm{~A} 4, \mathrm{~A} 5, \mathrm{~A} 8, \mathrm{~A} 9, \mathrm{~A} 16, \\
\mathrm{A} 17, \mathrm{~A} 18)\end{array}$ \\
\hline $\begin{array}{l}\text { Competition, } \\
\text { leaderboards, ranking }\end{array}$ & $\mathbf{5}(\mathrm{A} 1, \mathrm{~A} 3, \mathrm{~A} 4, \mathrm{~A} 5, \mathrm{~A} 17)$ \\
\hline Social elements & $3(\mathrm{~A} 1, \mathrm{~A} 4, \mathrm{~A} 17)$ \\
\hline $\begin{array}{l}\text { 'Shadowing' (previous } \\
\text { performance } \\
\text { visualization) }\end{array}$ & $2(\mathrm{~A} 6, \mathrm{~A} 15)$ \\
\hline Suggestions, advice & 1 (A5) \\
\hline Unspecified & $1(\mathrm{~A} 2)$ \\
\hline
\end{tabular}

The prevalence of the elements indicated in the analysis is, however, quite understandable given the type of the work that the gamification was most often targeted towards. In the reviewed studies, the work was mostly individual, well-defined, step-by-step work, thus easily allowing for the definition of multiple, intermediate objectives and goals, and providing (multimedial) feedback. Furthermore, for example, the lack of use of e.g. social aspects, which are today very common in gamification solutions [32], could be explained by the fact that the individual work requires an individual focus rather than a social/communal one. 
It should also be noted that many of the studies (notably studies A3, A6, A9, A14, A15, A16, and A18) offered a limited insight into the applied or considered motivational affordances. In these studies the design descriptions were often quite unclear or on a very general level. One study did not specify any motivational affordances at all (study A2).

\subsection{Psychological outcomes and behavioral or organizational impacts}

Table 3 lists psychological outcomes (expected or measured; the table's rows) and connects them to behavioral or organizational impacts (expected or measured; the table's columns) in each of the reviewed studies. Each cell references the individual publications that cover the particular outcome and impact.

Concerning psychological outcomes, 10 out of the 11 design research studies were either interested in or had measured in some form an increase in motivation, enjoyment (fun) or flow among the individual employees using the gamification. When these concepts were actually measured in the studies, they were mainly measured via (mostly self-developed) self-assessment questionnaires. Other considered psychological outcomes included alertness or presence of mind, awareness, learning, work focus (not being disturbed), engagement, happiness, and interest.

Concerning behavioral or organizational impacts, 9 out of the 11 design research studies were either interested in or had measured in some form an increase in performance or efficiency, mostly on the level of an individual worker. The studies were mainly concerned with improvement in quality of the product being produced (less errors made during production), improvement in amount of products produced in some timeframe, or fewer time or resources required for the involved production or transportation, all either per employee or overall. Other considered behavioral or organizational impacts included compliance, competence, employee involvement or turnover, job satisfaction, health, safety, communication, system/technology performance or efficiency, and work transparency. Overall, the publications focused much more on individual behavioral impacts than organizational impacts.

Several studies (most notably studies A14 and A18) made suggestive remarks about expected behavioral/organizational impacts, although it was not explicitly stated whether these were considered to be a part of the goal of the gamification solution, or just a means of arguing that the gamification is worth exploring. In Table 3, these notions are included as expected impacts nonetheless.

In terms of the results of the studies, 9 of the 11 empirical studies reported their findings. Most of these studies reported positively-oriented findings (6 out of the 9 studies: A1, A4, A10, A11, A16, A18). In the remaining three studies, some positive results were reported, but also null and/or negative results (studies A8, A12, A13). The empirical studies that did not report actual findings included a preliminary user study from which results were not comprehensively reported (study A5), and a simulation study (study A3).

Table 3. Psychological outcomes connected to behavioral and organizational impacts in the reviewed studies. The numbers refer to Appendix IDs.

\begin{tabular}{|c|c|c|c|c|c|c|c|}
\hline \multicolumn{2}{|c|}{ Behavioral/organizational impact: } & \multicolumn{3}{|l|}{ Expected } & \multicolumn{3}{|l|}{ Measured } \\
\hline & & Performance & Efficiency & Other* & Performance & Efficiency & Other** \\
\hline $\begin{array}{l}\text { Psychological } \\
\text { outcome: }\end{array}$ & Unspecified & & & & & & A3 \\
\hline & Motivation & $\begin{array}{c}\text { A6, A7, A9, } \\
\text { A17 }\end{array}$ & $\begin{array}{c}\text { A2, A6, A7, } \\
\text { A14, A17 }\end{array}$ & $\begin{array}{c}\text { A2, A9, } \\
\text { A14, A17 }\end{array}$ & A12 & A4, A12 & \\
\hline & Flow & A6, A9, A13 & $\begin{array}{c}\text { A6, A13, A14, } \\
\text { A15 }\end{array}$ & A9, A14 & A8, A12 & A8, A12 & \\
\hline & Enjoyment / 'fun' & & $\mathrm{A} 15$ & & & & \\
\hline & Other $* * *$ & A6 & A5, A6 & A5 & & & \\
\hline & Motivation & A10 & A10 & A16 & & & \\
\hline & Flow & & & A18 & & & \\
\hline & Enjoyment / 'fun' & A10, A11 & A10, A11 & & & & \\
\hline & Emotional state & & & A18 & A8 & A8 & \\
\hline & Other**** & $\begin{array}{l}\text { A10, A11, } \\
\text { A13 }\end{array}$ & $\mathrm{A} 10, \mathrm{~A} 11, \mathrm{~A} 13$ & $\begin{array}{c}\text { A1, A16, } \\
\text { A18 }\end{array}$ & A1 & & \\
\hline $\begin{array}{l}* \text { Including con } \\
* * \text { Including sy } \\
* * * \text { Including a } \\
* * * * \text { Including } \\
\text { demand, time p }\end{array}$ & $\begin{array}{l}\text { ce, competence, } \\
\text { technology perfor } \\
\text { ss/presence of mi } \\
\text { focus (not being } \\
\text { e, performance a }\end{array}$ & $\begin{array}{l}\text { nployee involve } \\
\text { nance or efficier } \\
\text { d, awareness, a } \\
\text { isturbed), engag }\end{array}$ & $\begin{array}{l}\text { ent or turnover, } \\
\text { y, and work tran } \\
\text { learning. } \\
\text { nent, happiness, }\end{array}$ & $\begin{array}{l}\text { satisfaction } \\
\text { rency. } \\
\text { erest, perce }\end{array}$ & of cognitiv & commui & $\begin{array}{l}\text { tion. } \\
\text { ical }\end{array}$ \\
\hline
\end{tabular}




\section{State of the research and future directions}

Based on the review of the body of research literature on gamification of production and logistics, it can be concluded that the research on the topic is currently in the piloting phase. Several reasons, mainly regarding the methodological and theoretical aspects of the studies, have led to this conclusion.

Firstly, only a slight majority of the reviewed studies conducted actual tests, and only a few applied rigorous experimental research designs. Concerning these (quasi-)experiments it should be noted that sample sizes were also fairly small, measurements were mostly conducted with unvalidated instruments, and statistical significance was practically never achieved. Moreover, in (quasi-)experimental designs, it is important that future studies compare any gamification solutions to the actual existing work standard or arrangement rather than a laboratory condition.

Secondly, as Table 3 shows, only one publication measured both psychological outcomes and behavioral/organizational impacts in the same study. This means that any other study did not explore the full chain of the gamification process including the affective as well as the behavioral outcomes. Based on this finding, we can conclude that the empirical research designs were generally not very comprehensive. This is a commonly noted limitation in gamification research [32][9][12] that should be paid more attention to in future research endeavors.

Thirdly, in-depth discussions on discrepancies between expected and observed effects or ramifications on observed effects were very rare. Such discussions were limited to a discussion of the discrepancy between expected emotional state (less negative, more positive) and observed emotional state of participants (less negative and positive) when comparing the gamified condition to the control condition (study A8).

Consequently, more experiments with theorydriven research designs (see e.g. [18][21]), that connect measured psychological outcomes to measured behavioral or organizational impacts, are required. This should also allow for more in-depth discussions of discrepancies or nuances between the expected and actual outcomes.

Furthermore, the review also highlights an important point for future research to consider, that is, where to draw the line on what constitutes gamification in the given context and what can be considered a motivational affordance or an important work/organizational design choice. An example of these challenges comes from the study A17, where it is demonstrated that in construction planning and control intermediate goals/objectives are constantly present; they are inherent to planning and control work. Thus, the field has been 'gamifying' the work long before the term became fashionable, or setting objectives and goals is not a particularly defining characteristic of gamification in this context.

In the domain of production and logistics, it seems that gamification has so far often been understood quite simplistically, deterministically and instrumentally, and consequently, approached without clearly specifying the motivational affordances or the undesired, expected or measured psychological outcomes or behavioral and organizational impacts. With this review, we have indeed found studies that reveal the instrumental appropriation of gaming elements in production and logistics. Yet gamification is always designed and applied specifically (though not always very explicitly) by someone, somewhere. For example, one could gamify the work 'as is' (e.g. add a scoring system and leaderboard) or start 'from scratch' and design a new way of working from a gamification perspective. This means that we should be at least cautious and skeptical towards generic causal or correlational statements pertaining to gamification; we can and should make specific claims about specific choices in gamification design, context and application. Even then we should contextualize our claims - what theoretical or philosophical underpinnings underlie them, do those under study share those underpinnings, what alternative underpinnings would shed different light on the subject?

Continuing this line of thought, we encourage the field to attempt to aim for more than performance or efficiency with the gamification designs, and to target areas such as process or product innovation. Moreover, the field can also seek for more tailor-made gamification, i.e., gamification that can be personalized more to suit differing backgrounds and needs of its participants. Technologically, advances made over the past decade have allowed computer games to adjust their rulesets based on continual assessment of players' competence or motivation level. Similar approaches could be adapted to gamification of work contexts.

The gamification of production and logistics is a fascinating field for organization theorists that has remained practically untapped. The field takes us very close to the sociology of work; and one could ride on Barley and Kunda's [2] call for bringing work back in by calling for also play to be brought back in. As already observed by the studies reviewed, production and logistics are at the very heart of 'serious business'. Thus, from an organizational point of view, the mere existence of gamification in such settings is counterintuitive. As stated by French sociologist Henri Lefebvre, 'When we are not playing (in other words 
when we are living seriously) we also come to decisions in the absence of adequate information, confronting chance and determinism and therefore playing in the deepest meaning of the word' [19]. The question remains, is there, truly, an independent space for gamification within organizational processes, or are we simply here addressing a quality of the social practice and sensemaking of ordinary work processes.

Consequently, we call for a richer understanding and thus study of gamification, and for a focus on the implicit negotiations between players, developers and appliers of gamification concerning how to interpret it, and whether to accept and appropriate it in the often highly structured and standardized work of production and logistics. It is here that we can turn to organization theory to search for frameworks that are better suited to understanding the gamification of productive and logistics work as a collective work effort. We would like to highlight the value of adapting a sensemaking perspective for understanding the interpretative processes, a practice perspective for understanding the actual everyday work, and a critical theory perspective for understanding the potentially exploitative nature of gamified working environments.

By focusing on sensemaking [36] we are better able to grasp the constant interpretation and reinterpretation of work life as it happens both in groups and on the individual level. Thus, rather than trying to prove the possible effects or let alone efficiency of gamification, it becomes important to understand the cognitive work performed within and in relation to gamified work. How do people collectively make sense of changes to production and logistics work processes that include gamified aspects? How do such processes, or elements, change how groups of people value their own work and how they approach tasks at hand? What are the moral and ethical consequences in the long run? Largely, these questions come down to understanding gamification as a type of organizational change; as one organizational design phenomenon alongside any other. Thus, we can learn more about the consequences of gamification by examining how phenomena such as managerial everyday coping [31][28], strategic change [1], or organizational (re)design [8] have been analyzed and by appropriating frameworks and research designs from such studies.

Furthermore, studying the actual practices of gamification at work is highly encouraged [27][33]. Scholars are encouraged to consider how exactly is gamification integrated into production and logistics, and are there clashes between the serious, work floor level practices and the playful aspects in organizational practice. Also, as indicated in this review, sometimes the production and logistics work tasks contain selfsustained gamified qualities. Research should pay attention to how these can or potentially should not be targeted in gamification.

Finally, we encourage gamification scholars to engage more profoundly with critical theory to understand the potentially problematic nature of the topic. What exactly is the underlying motive for rendering rather traditional working life of production and logistics into something playful? Such changes transform organizational discourses and practices; what is true and what can be talked about within the organizational frames [15]. Gamification can have substantial impacts on how work is valued, how strategies are formed and how power is exercised in the rather classical organizational contexts of production and logistics.

\section{Conclusions}

In summary, most of the 18 papers we identified for the review were empirical, design research-based studies into production execution and control, i.e., influencing workers completing tasks in the actual production process. The most commonly applied affordances in the studies were 'goals and objectives', 'multimedial feedback', and 'metaphorical/fictional representations'. The use of metaphorical/fictional representations of the work as well as the 'shadowing' of previous work (visualizing the worker's previous or recent work performance as a shadow behind the worker's current work performance to help benchmark it) is especially noteworthy, since they have not been addressed in previous reviews of gamification in contexts other than production and logistics [12]. Most design research studies were either interested in or in some form measured through self-assessments an increase in motivation, enjoyment (fun) or flow among the individual employees using the gamification. Furthermore, most were either interested in or measured an increase in performance or efficiency on the level of an individual worker, e.g. an improvement in quality of the product being produced (less errors made during production), improvement in amount of products produced in a timeframe, or fewer time or resources required for the involved production or transportation.

Finally, we have offered several considerations for improving and extending design research methodologies, all focused on increasing the clarity and rigor of the research. We have also suggested the influx of organization theory to the domain, notably sensemaking and critical-theory perspectives.

Regarding the limitations of our review, the literature search was limited only to the Scopus database. While we are confident of the 
comprehensiveness of our literature search, it is nevertheless possible that some publications have been missed due to either not being indexed in this database, or due to indexing errors (as is the case with any review study). We are, however, certain that the potential number of missed publications is small, and their inclusion would not significantly affect the results of the review.

\section{Acknowledgements}

This project has received funding from the European Union's Horizon 2020 research and innovation programme under grant agreement No 723661. http://www.cocop-spire.eu/

\section{References}

[1] Balogun, J., and Johnson, G., "From intended strategies to unintended outcomes: The impact of change recipient sensemaking", Organization studies, 26(11), 2005, 15731601 .

[2] Barley, S. R., and Kunda, G., "Bringing work back in", Organization science, 12(1), 2001, 76-95.

[3] Chase, R. B., Aquilano, N. J., and Jacobs, F. R., Production and operations management, Irwin/McGraw-Hill, 1998.

[4] Cherry, M. A., "The gamification of work", Hofstra Law Review, 40, 2012, 851-858.

[5] Christopher, M., Logistics \& supply chain management. Pearson UK, 2016.

[6] Cooper, M. C., Lambert, D. M., and Pagh, J. D., "Supply Chain Management: More Than a New Name for Logistics", The International Journal of Logistics Management, 8(1), 1997, 1-14.

[7] Dale, S., "Gamification: Making work fun, or making fun of work?", Business Information Review, 31(2), 2014, 82-90.

[8] Denis, J. L., Dompierre, G., Langley, A., and Rouleau, L., "Escalating indecision: Between reification and strategic ambiguity", Organization Science, 22(1), 2011, 225-244.

[9] Deterding, S., "The lens of intrinsic skill atoms: A method for gameful design", Human-Computer Interaction, 30(3-4), 2015, 294-335.

[10] Deterding, S., Dixon, D., Khaled, R., and Nacke, L. "From game design elements to gamefulness: defining gamification", In Proceedings of the 15th International Academic MindTrek Conference: Envisioning Future Media Environments, September 28-30, 2011, Tampere, Finland, ACM, pp. 9-15.

[11] Hamari, J., "Transforming Homo Economicus into Homo Ludens: A Field Experiment on Gamification in a Utilitarian Peer-To-Peer Trading Service", Electronic Commerce Research and Applications, 12, 2013.

[12] Hamari, J., Koivisto, J., and Sarsa, H., "Does Gamification Work? - A Literature Review of Empirical Studies on Gamification”, In Proceedings of the 47th Hawaii
International Conference on System Sciences, January 6-9, 2014, Hawaii, USA.

[13] Huotari, K., and Hamari, J., "Defining gamification: a service marketing perspective", In Proceedings of the 16th International Academic MindTrek Conference, October 3-5, 2012, Tampere, Finland, ACM, pp. 17-22.

[14] Huotari, K., and Hamari, J. "A definition for gamification: Anchoring gamification in the service marketing literature", Electronic Markets, 27(1), 2017, 2131.

[15] Knights, D., and Morgan, G., "Corporate strategy, organizations, and subjectivity: A critique", Organization studies, 12(2), 1991, 251-273.

[16] Koivisto, J., and Hamari, J., "Demographic differences in perceived benefits from gamification", Computers in Human Behavior, 35, 2014, 179-188.

[17] Korn, O., Schmidt, A., and Hörz, T., “Assistive systems in production environments: Exploring motion recognition and gamification", In ACM International Conference Proceeding Series, 2012.

[18] Kriz, W. C., and Hense, J. U., "Theory-oriented evaluation for the design of and research in gaming and simulation", Simulation \& Gaming, 37(2), 2006, 268-283.

[19] Lefebvre, H., Critique of everyday life. Verso Books, 2014.

[20] Liu, D., Santhanam, R., and Webster, J., "Towards Meaningful Engagement: A Framework for Design and Research of Gamified Information Systems", MIS Quarterly, 2017, in press.

[21] Mayer, I., Bekebrede, G., Harteveld, C., Warmelink, H., Zhou, Q., Van Ruijven, T., ... Wenzler, I., "The research and evaluation of serious games: Toward a comprehensive methodology", British Journal of Educational Technology, 45(3), 2014, 502-527.

[22] McGonigal, J., Reality is broken: Why games make us better and how they can change the world, London: Jonathan Cape, 2011.

[23] Morschheuser, B., Hamari, J., Koivisto, J., and Maedche, A., "Gamified Crowdsourcing: Conceptualization, literature review, and future Agenda", International Journal of Human-Computer Studies, 2017. DOI 10.1016/j.ijhcs.2017.04.005.

[24] Norman, D. A., The design of everyday things: Revised and expanded edition, New York: Basic books, 2013.

[25] Paré, G., Trudel, M. C., Jaana, M., and Kitsiou, S., "Synthesizing information systems knowledge: A typology of literature reviews", Information \& Management, 52(2), 2015, 183-199.

[26] Potente, T., Varandani, R., and Prote, J.-P., "Gamification in management decisions: Judging global production networks in a cyber-physical way", Advanced Materials Research, 769, 2013.

[27] Reckwitz, A., "Toward a theory of social practices a development in culturalist theorizing", European journal of social theory, 5(2), 2002, 243-263.

[28] Rouleau, L., "Micro-practices of strategic sensemaking and sensegiving: how middle managers interpret and sell change every day", Journal of Management studies, 42(7), 2005, 1413-1441.

[29] Ryan, R. M., and Deci, E. L., "Self-determination theory and the facilitation of intrinsic motivation, social 
development, and well-being", American Psychologist, 55(1), 2000, 68-78.

[30] Ryan, R. M., Rigby, C. S., and Przybylski, A., "The motivational pull of video games: A self-determination theory approach", Motivation and Emotion, 30(4), 2006, 344-360.

[31] Samra-Fredericks, D., "Strategizing as lived experience and strategists' everyday efforts to shape strategic direction", Journal of management studies, 40(1), 2003, 141-174.

[32] Seaborn, K., and Fels, D. I., "Gamification in theory and action: A survey", International Journal of Human Computer Studies, 74, 2015, 14-31.

[33] Vaara, E., and Whittington, R., "Strategy-as-practice: taking social practices seriously", The Academy of Management Annals, 6(1), 2012, 285-336.
[34] Vesa, M., Hamari, J., Harviainen, J. T., and Warmelink, H., "Computer Games and Organization Studies", Organization Studies, 38(2), 2017, 273-284.

[35] Webster, J., and Watson, R. T., "Analyzing the Past to Prepare for the Future: Writing a Literature Review," MIS Quarterly, 26(2), 2002, xiii-xxiii.

[36] Weick, K. E., Sensemaking in organizations (Vol. 3), Sage, 1995.

[37] Xu, L. D., He, W., and Li, S., "Internet of Things in Industries: A Survey", IEEE Transactions on Industrial Informatics, 10(4), 2014, 2233-2243.

\section{Appendix}

\section{Appendix A. A full list of the reviewed research papers.}

\begin{tabular}{|c|c|}
\hline ID & ull citation \\
\hline A1 & $\begin{array}{l}\text { Inha Leite, R. M., Costa, D. B., Neto, H. M. M., \& Durão, F. A. (2016). Gamification technique for supporting } \\
\text { insparency on construction sites: A case study. Engineering, Construction and Architectural Management, 23(6). }\end{array}$ \\
\hline A2 & $\begin{array}{l}\text { Hense J., Klevers M., Sailer M., Horenburg T., Mandl H., Günthner W. (2014) Using Gamification to Enhance Staff } \\
\text { Motivation in Logistics. Lecture Notes in Computer Science, vol 8264. Springer, Cham. }\end{array}$ \\
\hline A3 & $\begin{array}{l}\text { Herzig, P., Wolf, B., Brunstein, S., \& Schill, A. (2013). Efficient persistency management in complex event } \\
\text { processing: A hybrid approach for gamification systems. Lecture Notes in Computer Science (Vol. } 8035 \text { LNCS). }\end{array}$ \\
\hline A4 & $\begin{array}{l}\text { Kampker, A., Deutskens, C., Deutschmann, K., Maue, A., \& Haunreiter, A. (2014). Increasing ramp-up performance } \\
\text { by implementing the gamification approach. In Procedia CIRP (Vol. 20). }\end{array}$ \\
\hline A5 & $\begin{array}{l}\text { Klemke, R., Kravcik, M., \& Bohuschke, F. (2014). Energy-efficient and safe driving using a situation-aware } \\
\text { gamification approach in logistics. Lecture Notes in Computer Science (Vol. 8605). }\end{array}$ \\
\hline A6 & $\begin{array}{l}\text { Korn, O. (2012). Industrial playgrounds: How gamification helps to enrich work for elderly or impaired persons in } \\
\text { production. In Proceedings of the } 2012 \text { ACM SIGCHI Symposium on Engineering Interactive Computing Systems. }\end{array}$ \\
\hline A7 & $\begin{array}{l}\text { Korn, O., \& Schmidt, A. (2015). Gamification of Business Processes: Re-designing Work in Production and Service } \\
\text { Industry. Procedia Manufacturing, } 3 \text {. }\end{array}$ \\
\hline A8 & $\begin{array}{l}\text { Korn, O., Boffo, S., \& Schmidt, A. (2015). The effect of gamification on emotions - the potential of facial recognition } \\
\text { in work environments. Lecture Notes in Computer Science (Vol. 9169). }\end{array}$ \\
\hline A9 & $\begin{array}{l}\text { Korn, O., Funk, M., \& Schmidt, A. (2015). Assistive systems for the workplace: Towards context-aware assistance. } \\
\text { Gamification: Concepts, Methodologies, Tools, and Applications (Vol. 4-4). }\end{array}$ \\
\hline A10 & $\begin{array}{l}\text { Korn, O., Funk, M., \& Schmidt, A. (2015). Design approaches for the gamification o } \\
\text { study focusing on acceptance. In Proceedings of PETRA '15 - ACM International Confe }\end{array}$ \\
\hline A11 & $\begin{array}{l}\text { Korn, O., Funk, M., \& Schmidt, A. (2015). Towards a gamification of industrial p } \\
\text { sheltered work environments. In Proceedings of the EICS } 2015 \text { ACM SIGCHI Symp }\end{array}$ \\
\hline A12 & $\begin{array}{l}\text { Korn, O., Funk, M., Abele, S., Hörz, T., \& Schmidt, A. (2014). Context-aware assisti } \\
\text { Analyzing the effects of projection and gamification. In ACM International Conference P }\end{array}$ \\
\hline A13 & $\begin{array}{l}\text { Korn, O., Lang, J., Korge, A., Causegic, H., \& Schmidt, A. (2016). Gamifica } \\
\text { in sheltered employment. In Conference on Human Factors in Computing Sys }\end{array}$ \\
\hline A14 & $\begin{array}{l}\text { Korn, O., Muschick, P., \& Schmidt, A. (2017). Gamification of production? A study } \\
\text { work processes in the automotive industry. Advances in Intelligent Systems and Comput }\end{array}$ \\
\hline A15 & $\begin{array}{l}\text { Korn, O., Schmidt, A., \& Hörz, T. (2012). Assistive systems in production environments: Exploring motion } \\
\text { recognition and gamification. In ACM International Conference Proceeding Series. }\end{array}$ \\
\hline A16 & $\begin{array}{l}\text { Lee, J., Kim, J., Seo, K., Roh, S., Jung, C., Lee, H., ... Ryu, H. (2016). A case study in an automotive assembly line: } \\
\text { Exploring the design framework for manufacturing gamification. Advances in Intelligent Systems and Computing } \\
\text { (Vol. 490). }\end{array}$ \\
\hline A17 & $\begin{array}{l}\text { Neto, H. M., Leite, R. M., Costa, D. B., \& Durão, F. (2014). Visual communication panels for production control using } \\
\text { gamification techniques. In 22nd Annual Conference of the International Group for Lean Construction: Understanding } \\
\text { and Improving Project Based Production. }\end{array}$ \\
\hline A18 & $\begin{array}{l}\text { Roh, S., Seo, K., Lee, J., Kim, J., Ryu, H. B., Jung, C., ... Shin, J. (2016). Goal-based manufacturing gamification: } \\
\text { Bolt tightening work redesign in the automotive assembly line. Advances in Intelligent Systems and Computing (Vol. } \\
\text { 490). }\end{array}$ \\
\hline
\end{tabular}

